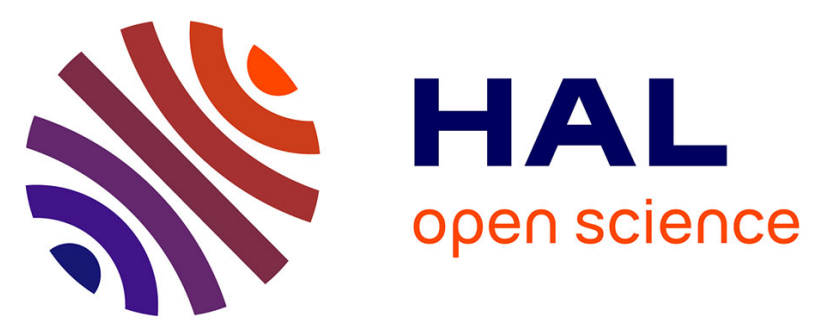

\title{
Layered double hydroxide - borate composites supported on magnetic nanoparticles: preparation, characterization and molecular dynamics simulations
}

\author{
Ahmet Nedim Ay, Birgul Zumreoglu-Karan, Andrey G. Kalinichev, Vicente \\ Rives, Raquel Trujillano, Abidin Temel
}

\section{To cite this version:}

Ahmet Nedim Ay, Birgul Zumreoglu-Karan, Andrey G. Kalinichev, Vicente Rives, Raquel Trujillano, et al.. Layered double hydroxide - borate composites supported on magnetic nanoparticles: preparation, characterization and molecular dynamics simulations. Journal of Porous Materials, 2020, 27, pp.735-743. 10.1007/s10934-019-00853-4 . hal-03521798

\author{
HAL Id: hal-03521798 \\ https://hal.science/hal-03521798
}

Submitted on 15 Feb 2022

HAL is a multi-disciplinary open access archive for the deposit and dissemination of scientific research documents, whether they are published or not. The documents may come from teaching and research institutions in France or abroad, or from public or private research centers.
L'archive ouverte pluridisciplinaire HAL, est destinée au dépôt et à la diffusion de documents scientifiques de niveau recherche, publiés ou non, émanant des établissements d'enseignement et de recherche français ou étrangers, des laboratoires publics ou privés. 
1 Layered Double Hydroxide-Borate Composites Supported on Magnetic Nanoparticles: Preparation, Characterization and Molecular Dynamics Simulations

3

Ahmet Nedim Ay, ${ }^{* 1}$ Birgul Zumreoglu-Karan, ${ }^{1}$ Andrey G. Kalinichev, ${ }^{2,}{ }^{3}$ Vicente Rives, ${ }^{4}$ Raquel Trujillano, ${ }^{4}$ and Abidin Temel ${ }^{5}$

(

Abstract Magnetic nanocomposites involving tetraborate ion (TB)-intercalated Mg-Allayered double hydroxide (LDH) shell supported on magnesium ferrite (MF) core particles are synthesized, characterized, and compared with their non-magnetic analogues. The compositions of the obtained nanocomposites were determined and structural investigations were made by powder X-ray diffraction (PXRD) and Fourier transform infrared spectroscopy (FT-IR). Particle characteristics were examined by size distribution, specific surface area measurements, scanning electron microscopy (SEM) and transmission electron microscopy (TEM). Room-temperature magnetic measurements were performed with a vibrating sample magnetometer (VSM). The dynamics and structure of the interlayer water molecules and borate ions were studied by molecular dynamics (MD) simulations. Analytical and modeling studies verified that the TB ions were arranged between the LDH layers in oblique positions. The products were found to carry ca. $6 \%$ boron $\left(10^{17} \mathrm{~B}\right.$ atom/ $/ \mu \mathrm{g}$ nanocomposite). The magnetic nanocomposite showed superparamagnetic properties and can potentially find applications in biomedical fields for the site-specific delivery of bio-potent boron agents.

Keywords Magnetic nanocomposites · Layered double hydroxides · Intercalation · Boron · Borate composites · Molecular dynamics simulations 
$27 \bowtie$ Ahmet Nedim Ay

281 Department of Chemistry, Hacettepe University, 06800 Ankara, Turkey. E-mail: 29 ay@hacettepe.edu.tr; Fax: +90 312 2992163; Tel: +90 3122976268

$30 \quad{ }^{2}$ SUBATECH (UMR 6457 - IMT Atlantique, Université de Nantes, CNRS/IN2P3), France.

$31{ }^{3}$ International Laboratory SAMMA, National Research Univ. Higher School of Economics, 32 Moscow, Russia.

$33{ }^{4}$ GIR- QUESCAT, Department of Inorganic Chemistry, University of Salamanca, 3700834 Salamanca, Spain.

$35{ }^{5}$ Department of Geological Engineering, Hacettepe University, 06800, Ankara, Turkey. 36 


\section{Introduction}

Layered double hydroxide (LDH) materials have unique adsorption and transport properties and high surface areas allowing accommodation of anionic components in the interlayer space [1]. Over the last decade, LDH-based hierarchical architectures have gained an increasing interest for various specific applications due to their multifunctional properties [2,3]. The introduction of oxoanions or polyoxoanions in the LDH structure is a growing area of research for applications in energy, catalysis, biomedical and environmental sciences $[4,5]$. The uptake of borate ions from aqueous solutions has been studied most widely with Mg-AlLDHs, and several LDH-borate composites have thus been suggested for miscellaneous purposes [6]. Shi et. al. [7] reported a borate pillared Mg-Al-carbonate-LDH with flameretardant and smoke-suppressant properties. Elmaci et. al. [8] showed that Mg-Al-LDH can be used in boron isotopic enrichment applications. Boron containing Ca-Al-LDH has been suggested as an active, selective and recyclable catalyst in Beckmann type reactions [9]. However, because of the strong interactions between the charged LDH sheets and the inherent interlayer anions (nitrate, carbonate, etc.), direct intercalation of the large polyborate anions is a difficult task. Li et. al. [10] reported a hydrothermal method for the intercalation of tetraborate (TB) ions into $\mathrm{Mg}-\mathrm{Al}-\mathrm{NO}_{3}-\mathrm{LDH}$. It was later shown that polyborate anions can be intercalated by the ion exchange method [11] and well textured materials containing TB ions can be obtained around $\mathrm{pH}$ 9, either with or without using interlayer space expanding long chain organic anions [12].

LDHs are biocompatible materials [13] while boron is a vital element not only for plants but also for human body with many physiological and therapeutic functions [14-19]. The role of boron in preventing arthritis and fungal infections, regulating pheromone levels, enhancing cognition and bone health, and treating cancer has been emphasized among the many beneficial effects of boron. A nanohybrid of a boron compound with non-toxic LDH is 
expected to act as an effective agent for boron neutron capture therapy (BNCT) [20]. To provide a satisfactory boron concentration at the desired target site, carborane derivatives $[21,22]$ or inorganic polyborate ions can be used as the intercalating species. In biological systems, boron is present as un-dissociated boric acid $\left[\mathrm{B}(\mathrm{OH})_{3}\right]$ and as borate ion $\left[\mathrm{B}(\mathrm{OH})_{4}\right]^{-}$ $[23,24]$. The use of polyborate ions from borax or similar borate salts is therefore attractive due to their good water solubility, relatively low toxicity and the simplicity in their implementation.

Boron has the capacity to bind covalently to biological targets and a promising sitespecific application is the direction of boron to the target by means of an external magnetic field [25]. Supporting a polyborate-LDH nanohybrid on a magnetic core can further help sitespecific concentration of boron in biomedical applications [3]. In the past few years, several magnetic core-shell nanohybrid systems have been described for boron-delivery including anionic boron cluster-graphene oxide [26], vitamin C-borate [27], carborane-layered double hydroxide (LDH) [18], carboranylphosphinate [28], and rare earth-borate [29].

This work reports the preparation, characterization and atomistic computer simulations of nanocomposites involving TB-intercalated Mg-Al-LDH and its magnetic core-shell counterpart supported on $\mathrm{MgFe}_{2} \mathrm{O}_{4}$ particles.

\section{Materials and methods}

\subsection{Chemicals}

$$
\mathrm{Mg}\left(\mathrm{NO}_{3}\right)_{2} \cdot 6 \mathrm{H}_{2} \mathrm{O} \quad \text { (Sigma), } \quad \mathrm{Al}\left(\mathrm{NO}_{3}\right)_{3} \cdot 9 \mathrm{H}_{2} \mathrm{O} \quad \text { (Carlo-Erba), } \mathrm{NaOH} \quad \text { (Merck), }
$$

$\left(\mathrm{NH}_{4}\right)_{2} \mathrm{~B}_{4} \mathrm{O}_{7} \cdot 4 \mathrm{H}_{2} \mathrm{O}$ (Aldrich), and $\mathrm{Fe}\left(\mathrm{NO}_{3}\right)_{3} \cdot 9 \mathrm{H}_{2} \mathrm{O}$ (Sigma), were used as received. All experiments were performed under nitrogen atmosphere in decarbonated deionized water (DDW) to prevent the incorporation of atmospheric carbon dioxide as carbonate species into the LDH structure. 
Magnesium ferrite (MF) particles were synthesized as described by Ay et. al. [30]. A $100 \mathrm{~mL}$ solution of $\mathrm{Mg}\left(\mathrm{NO}_{3}\right)_{2} \cdot 6 \mathrm{H}_{2} \mathrm{O}(0.04 \mathrm{~mol})$ and $\mathrm{Fe}\left(\mathrm{NO}_{3}\right)_{3} \cdot 9 \mathrm{H}_{2} \mathrm{O}(0.08 \mathrm{~mol})$ and a second solution $(220 \mathrm{~mL})$ containing $\mathrm{NaOH}(0.38 \mathrm{~mol})$ and $\mathrm{Na}_{2} \mathrm{CO}_{3}(0.32 \mathrm{~mol})$ were simultaneously added into a three-neck flask. The resulting suspension with a pH of ca. 9 was stirred for $6 \mathrm{~h}$ at $100{ }^{\circ} \mathrm{C}$. The final precipitate, a non-stoichiometric $\mathrm{Mg}-\mathrm{Fe}-\mathrm{CO}_{3}-\mathrm{LDH}\left(\mathrm{CO}_{3}-\mathrm{LDH}\right)$, was separated by centrifugation, washed several times with deionized water, dried at room temperature and then calcined at $900{ }^{\circ} \mathrm{C}$ for $2 \mathrm{~h}$ to give the magnetic core material, $\mathrm{MgFe}_{2} \mathrm{O}_{4}$.

\subsection{Nanocomposite synthesis}

Nanocomposite synthesis was carried out in a stepwise manner. Mg-Al-NO $\mathrm{N}_{3}-\mathrm{LDH}$ was in situ deposited on MF core particles and then the interlayer nitrate ions were exchanged with TB ions [12].

\section{Syntheses of $\mathrm{Mg}-\mathrm{Al}-\mathrm{NO}_{3}-\mathrm{LDH}$ and $\mathrm{Mg}-\mathrm{Al}-\mathrm{TB}-\mathrm{LDH}$}

Mg-Al-NO $3-\mathrm{LDH}$ and Mg-Al-TB-LDH were prepared as reference materials. A 12 $\mathrm{mL}$ solution of $2 \mathrm{M} \mathrm{KOH}$ was added dropwise onto $60 \mathrm{~mL}$ of a solution containing $\mathrm{Mg}\left(\mathrm{NO}_{3}\right)_{2} \cdot 6 \mathrm{H}_{2} \mathrm{O}(20.51 \mathrm{~g}, 0.08 \mathrm{~mol})$ and $\mathrm{Al}\left(\mathrm{NO}_{3}\right)_{3} \cdot 9 \mathrm{H}_{2} \mathrm{O}(15.01 \mathrm{~g}, 0.04 \mathrm{~mol})(\mathrm{Mg} / \mathrm{Al}$ molar ratio=2). The resulting suspension was refluxed for 4 hours. The $\mathrm{pH}$ of the suspension was adjusted to 9.5 with $\mathrm{KOH}$. The precipitate formed was aged for 6 days at room temperature under nitrogen atmosphere, then washed with DDW and filtered. A $250 \mathrm{~mL}$ portion of DDW was added onto the filtered precipitate $\left(\mathrm{NO}_{3}-\mathrm{LDH}\right)$ and the final suspension was kept for further studies. $100 \mathrm{~mL}$ of $0.26 \mathrm{M}$ ammonium tetraborate solution was added to $75 \mathrm{~mL}$ of the $\mathrm{NO}_{3}-\mathrm{LDH}$ suspension under nitrogen atmosphere $(\mathrm{pH}=8.8)$ and refluxed for 4 hours. The product (TB-LDH) was filtered, washed and dried in a vacuum desiccator.

\section{Deposition of $\mathrm{NO}_{3}-\mathrm{LDH}$ shell on MF core particles}


A $34 \mathrm{~mL}$ solution containing $\mathrm{Mg}\left(\mathrm{NO}_{3}\right)_{2} \cdot 6 \mathrm{H}_{2} \mathrm{O}(5.27 \mathrm{~g}, 0.02 \mathrm{~mol})$ and $\mathrm{Al}\left(\mathrm{NO}_{3}\right)_{3} \cdot 9 \mathrm{H}_{2} \mathrm{O}$ (3.86 g, $0.01 \mathrm{~mol})(\mathrm{Mg} / \mathrm{Al}$ molar ratio =2) and $30 \mathrm{~mL}$ of $2 \mathrm{M} \mathrm{NaOH}$ solution were added dropwise to $30 \mathrm{~mL}$ aqueous dispersion of $0.2 \mathrm{~g}$ MF ( $\mathrm{pH}$ 9.5). The mixture was refluxed and then aged for 6 days at room temperature under nitrogen atmosphere. The product (LDH/MF) was filtered, washed and kept dispersed into $120 \mathrm{~mL}$ of water $(50 \mathrm{~mL}$ of this suspension contains $0.61 \mathrm{~g} \mathrm{LDH/MF).}$

\subsection{Intercalation of TB anions into the LDH-MF structure}

$50 \mathrm{~mL}$ of the LDH-MF suspension was added to $100 \mathrm{~mL}$ of $0.23 \mathrm{M}$ ammonium tetraborate solution and the suspension was refluxed for 4 hours. The product (TB-LDH/MF) was filtered, washed and dried in a vacuum desiccator.

\subsection{Characterization studies}

Powder X-ray diffraction analyses of the samples were performed with a Rigaku D/MAX-2200 diffractometer instrument using graphite-filtered $\mathrm{CuK} \alpha$ radiation ( $\lambda=1.54056 \AA)$ at a scanning rate of $4^{\circ} \mathrm{min}^{-1}$, from 3 to $70^{\circ}(2 \theta)$. FTIR spectra were recorded with a Perkin Elmer Spectrum One instrument using the KBr pellet technique in the 4000 $400 \mathrm{~cm}^{-1}$ range. Thermogravimetric and differential thermal analyses (TGA and DTA) were performed under dynamic nitrogen atmosphere $\left(30 \mathrm{~mL} \mathrm{~min}^{-1}\right)$ at a heating rate of $10^{\circ} \mathrm{C} \mathrm{min}{ }^{-1}$ on a Shimadzu DTG-60H thermal analysis system. Mg, Al, Fe and B contents of the samples were determined in a Yobin Ivon Ultima II model ICP-OES instrument. Particle size distribution analyses were performed with a Malvern Mastersizer 2000 instrument with a Mastersizer software programme. Analyses were carried out according to Lorenz-Mie theory by using 1.33 and 1.52 refractive indexes for water and for the samples, respectively. Specific surface area measurements were performed by recording the nitrogen adsorption-desorption isotherms at $-196^{\circ} \mathrm{C}$ with a Micromeritics Gemini VII 2390t equipment, Surface Area and 
Porosity analyser. All samples were degassed before analysis at $110^{\circ} \mathrm{C}$ in a Micromeritics Flowprep 060 Sample Degass System for 2 hours. Scanning Electron Microscopy (SEM) images were recorded on a FEI Quanta 200 FEG SEM system. Transmission Electron Microscopy (TEM) images were recorded with FEI Tecnai G2 F30 instrument at 300 or 100 $\mathrm{kV}$. Room temperature magnetization measurements were performed on a Quantum Designed Physical Property Measurement System with a vibrating sample magnetometer in a magnetic field range of $30 \mathrm{kOe}$.

\subsection{Computational Molecular Modeling}

To better understand the molecular mechanism of borate ions intercalation into the Mg-Al-LDH interlayers, their swelling behavior, and equilibrium interlayer water content, molecular dynamics (MD) computer simulations were carried out at ambient conditions ( $T=300 \mathrm{~K} ; P=0.1 \mathrm{MPa}$ ) for several hydration states using standard MD algorithms for the NPT statistical ensemble (constant number of atoms, constant pressure, and constant temperature) [31].

Based on the experimentally determined sample composition, the computational models were constructed using the same approach as in earlier simulations of Mg-Al-LDH intercalated with organic anions [32, 33]. The experimentally known Mg-Al-LDH crystal structure [34] was taken as the initial configuration of the primary layers in our models.

Guided by available X-ray absorption spectroscopy (XAS) and nanoscale imaging experimental data, indicating significant short-range cation ordering within the LDH layers [35,36], a completely ordered Mg, Al cation distribution in the hydroxide layers was assumed, and the simulation supercell consisted of $6 \times 6 \times 1$ crystallographic unit cells with rhombohedral $(R \overline{3} m)$ symmetry. However, these simulation supercells were eventually converted to the lowest $P 1$ symmetry and each crystallographic parameter was allowed to vary independently during energy minimization and the subsequent MD simulation using the NPT statistical 
ensemble. Thus, in the simulated models each $\mathrm{Al}$ octahedron had six nearest-neighbor $\mathrm{Mg}$ octahedra, and each Mg octahedron has three nearest-neighbor Mg-octahedra and three nearest-neighbor Al-octahedra (see Fig.3 below).

ClayFF force field [37] was used to describe the interatomic interactions among the LDH layers and water, while the DREIDING force field [38], was adopted for the borate ions and their interaction with $\mathrm{H}_{2} \mathrm{O}$ molecules and LDH layers, because ClayFF does not include atomic parameters for boron. The atomic partial charges for the borate ions were determined using the Qeq charge equilibration procedure [39]. Both DREIDING and ClayFF force fields have already been proven successfully accurate in multiple simulations of LDH materials intercalated by a wide range of inorganic and organic anions [32,33,40,41]. (A complete list of the force field parameters describing the energy of interatomic interactions in the simulated systems is provided in Supplementary Information). All simulations were performed using the Forcite Plus module of the Materials Studio molecular modeling software package [42] and started from energy- and stress-minimized structures. As usual, periodic boundary conditions were applied and Ewald summation was used to account for the long-range electrostatic interactions in the system (e.g., [31]). The equations of atomic motion were numerically integrated with a time step of $1 \mathrm{fs}$. The initial 50 ps period of each MD-simulated trajectory was used for equilibration, while the subsequent 100 ps of each trajectory was recorded every 10 fs for further statistical analysis.

\section{Results and discussion}

\subsection{Structural characterization of TB-LDH/MF nanocomposites}




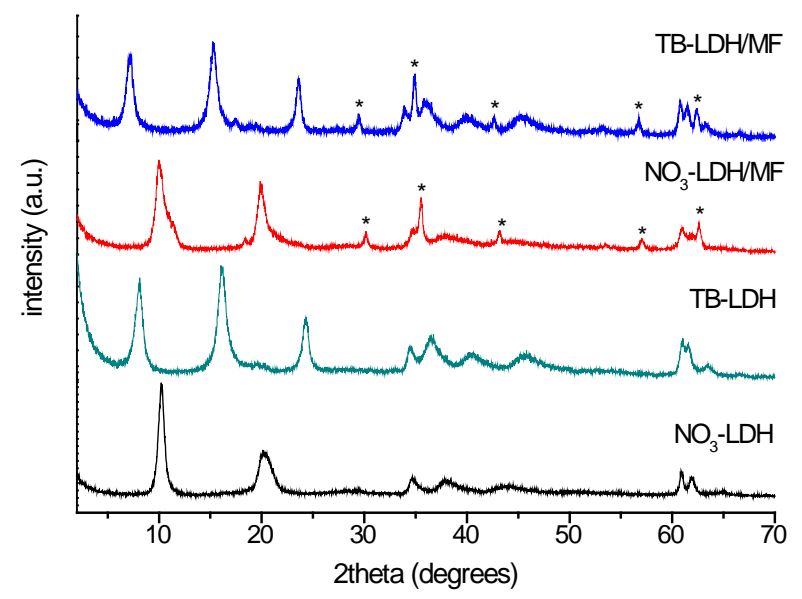

Fig. 1 Powder XRD patterns of $\mathrm{NO}_{3}-\mathrm{LDH}, \mathrm{TB}-\mathrm{LDH}, \mathrm{NO}_{3}-\mathrm{LDH} / \mathrm{MF}$ and TB-LDH /MF. MF reflections are marked as *

Fig.1 and Fig.S1 show the powder XRD patterns of the samples. The pattern for $\mathrm{NO}_{3}-\mathrm{LDH}$ is characteristic for Mg-Al-LDH having exchangeable nitrate ions [43]. The $d$-spacing of this LDH sample was calculated as $8.6 \AA$ from the $d_{003}$ reflection observed at $2 \theta=9.9^{\circ}$, using the Bragg equation, suggesting that the nitrate anions are not located flat, parallel to the layers, but somewhat tilted. This tilted orientation expands the LDH structure and favors exchange even with bulkier ions $[11,44]$. After exchanging the interlayer nitrate ions with the larger TB ions, a swelling of the interlayer space is observed, the position of the $d_{003}$ peak changed and the $d$-spacing increased to $10.89 \AA$. The height of the interlayer was calculated as $6.09 \AA$ after subtracting the layer thickness (4.8 $\AA$ ) from the $d$-spacing value [45]. The XRD pattern of $\mathrm{NO}_{3}-\mathrm{LDH} / \mathrm{MF}$ displayed both the LDH $\left(2 \theta=9.9^{\circ}, 19.8^{\circ}, 34.6^{\circ}\right)$ and $\mathrm{MF}\left(2 \theta=30.2^{\circ}, 35.5^{\circ}\right.$, $43^{\circ}, 57^{\circ}, 62.6^{\circ}$ ) reflections, indicating the composite nature of the sample. The pattern for TB-LDH/MF was quite similar to that of TB-LDH, but with additional MF reflections, with a interlayer space of $6.09 \AA$.

The TB ion consists of a hybrid configuration of two trigonal $\left(\mathrm{BO}_{3}\right)$ and two tetrahedral 198 $\left(\mathrm{BO}_{4}\right.$ ) groups (Fig. 2a-c). $\left(\mathrm{NH}_{4}\right)_{2} \mathrm{~B}_{4} \mathrm{O}_{7} \cdot 4 \mathrm{H}_{2} \mathrm{O}$ (which is also called ammonium borax), presents 
a very similar structure to that of borax $[46,47]$, it therefore seems probable that the crystal contains $\mathrm{B}_{4} \mathrm{O}_{9}$ groups $\left[\mathrm{B}_{4} \mathrm{O}_{5}(\mathrm{OH})_{4}\right]^{2-}$ rather than $\mathrm{B}_{4} \mathrm{O}_{7}{ }^{2-}$ ions. Considering the dimensions of the horizontal (Fig. 2a), vertical (Fig. 2b) or oblique (Fig. 2c) configurations of the TB ions [48-50], oblique positioning appears to be reasonable in the interlayer space of $6.09 \AA$ width.
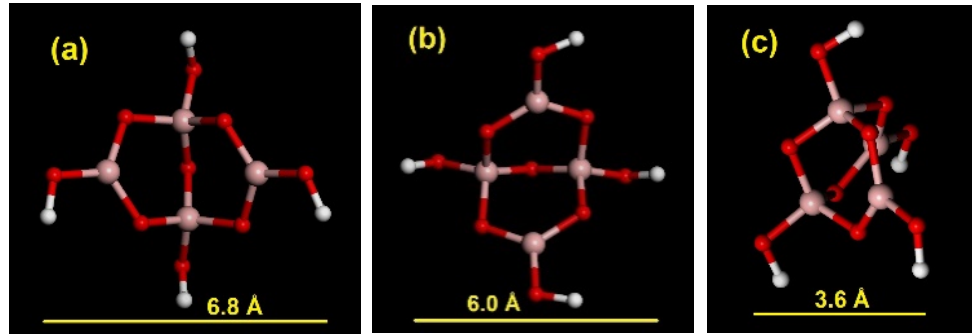

Fig. 2 Geometry-optimized atomic structure of the TB ion, $\left[\mathrm{B}_{4} \mathrm{O}_{5}(\mathrm{OH})_{4}\right]^{2-}$, in three different orientations (a: horizontal, b: vertical, c: oblique). (Pink - boron; red - oxygen; white hydrogen)

Although the $d$-spacing was large enough to allow accommodation of TB ions, it is not exactly diagnostic for the characterization of the intercalated borate ions as polymerization of borate species is very sensitive to $\mathrm{pH}$ and the molecular sizes of the polyborate ions are also very similar. So, the nature of the species can best be determined by ${ }^{11} \mathrm{~B}$ MAS NMR analysis. Considering the previous ${ }^{11} \mathrm{~B}$ MAS NMR studies on borate-LDH systems prepared via similar synthetic procedures and experimental condition [10,11], we can here conclude that the nature of the interlayer ion would be the same, namely tetraborate.

The FT-IR spectrum (Fig.S2) of the $\mathrm{NO}_{3}-\mathrm{LDH}$ sample is characteristic for LDHs containing nitrate ions between the layers. The strong and sharp peaks at 1384 and $826 \mathrm{~cm}^{-1}$ refer to the $v_{3}$ and $v_{2}$ vibration modes, respectively, of the interlayer nitrate ion. The strong and broad bands around $3450 \mathrm{~cm}^{-1}$ are due to the $\mathrm{O}-\mathrm{H}$ stretching vibrations of the hydroxyl groups in brucite layers and interlayer water molecules. After ion exchange with the TB ions, 
the intensity of the nitrate bands decreased while new bands appeared at 1478 and $1353 \mathrm{~cm}^{-1}$ $\left\{v_{\text {as }}\left(\mathrm{B}_{3}-\mathrm{O}\right)\right\}, 1200-850 \mathrm{~cm}^{-1}\{$ tetrahedral borate vibrations $\}, 1022 \mathrm{~cm}^{-1}\left\{\mathrm{v}_{\mathrm{as}}\left(\mathrm{B}_{4}-\mathrm{O}\right)\right\}, 934 \mathrm{~cm}^{-1}$ $\left\{v_{s}\left(B_{3}-O\right)\right\}$ and $811 \mathrm{~cm}^{-1}\left\{v_{s}\left(B_{4}-O\right)\right\}$ confirming the incorporation of the TB ions into the LDH structure [47]. The spectrum recorded for the TB-LDH/MF hybrid displayed the characteristic bands of the TB-LDH structure, while the characteristic spinel ferrite vibrations at $570 \mathrm{~cm}^{-1}\left(v_{1}\right)$ and $439 \mathrm{~cm}^{-1}\left(v_{2}\right)$ probably overlapped with the Mg-O and Al-O bands in the same region (Fig. S2).

\subsection{Chemical composition}

The samples were analyzed for their Fe, $\mathrm{Mg}, \mathrm{Al}$ and $\mathrm{B}$ contents by ICP-OES and for their $\mathrm{H}_{2} \mathrm{O}$ content by TGA. TGA data were also useful for the verification of the thermal stabilities of the composites [51].

The general behavior observed in the TGA curves shown in Fig.S3, can be interpreted as follows: surface water was removed up to $\sim 150{ }^{\circ} \mathrm{C}$, followed by the removal of the water molecules between the layers up to $\sim 250{ }^{\circ} \mathrm{C}$. Dehydroxylation of the brucite layers and the decomposition of the interlayer anions took place at higher temperatures up to $\sim 600{ }^{\circ} \mathrm{C}$ for $\mathrm{NO}_{3}-\mathrm{LDH}$ and $\sim 700{ }^{\circ} \mathrm{C}$ for TB-LDH. The shift in the decomposition offset temperatures indicated an increase in the thermal stability of the structure due to the pillaring effect of the incorporated TB ions. The total mass loss (54\%) recorded up to $600{ }^{\circ} \mathrm{C}$ for the $\mathrm{NO}_{3}-\mathrm{LDH}$ sample was higher than the total mass loss (32\%) recorded up to the same temperature for the TB-LDH sample. The interlayer nitrate ions thermally decomposed to gaseous $\mathrm{NO}_{\mathrm{x}}$ species and were removed out with the carrier gas while the TB ions transformed into $\mathrm{B}_{2} \mathrm{O}_{3}$, which remains as a permanent species. This difference (evolution of gases and formation of permanent solid species) would account for the difference observed in the mass losses 
recorded. The thermal analysis curve recorded for the TB-LDH/MF sample was quite similar to that of the TB-LDH sample.

Table 1 summarizes the proposed formulae for non-magnetic and magnetic nanocomposites based on the chemical analysis results, TGA water contents and assuming that TB ions were intercalated as $\left[\mathrm{B}_{4} \mathrm{O}_{5}(\mathrm{OH})_{4}\right]^{2-}$. The experimental and calculated values are in good agreement.

Table 1. Chemical compositions of the samples with some analytical data. (Values in the parentheses are calculated from the proposed formulae).

\begin{tabular}{|c|c|c|c|c|c|c|}
\hline \multirow{2}{*}{ Sample } & Formula & $\mathrm{Mg}$ & $\mathrm{Al}$ & $\mathrm{B}$ & $\mathrm{Fe}$ & $\mathrm{H}_{2} \mathrm{O}$ \\
& & $(\%)$ & $(\%)$ & $(\%)$ & $(\%)$ & $(\%)$ \\
\hline TB-LDH & {$\left[\mathrm{Mg}_{0.67} \mathrm{Al}_{0.33}(\mathrm{OH})_{2}\right]\left[\mathrm{B}_{4} \mathrm{O}_{5}(\mathrm{OH})_{4}\right]_{0.165} \cdot 0.7 \mathrm{H}_{2} \mathrm{O}$} & $(15.5)$ & $(8.63)$ & $(7.00)$ & - & $(14.13)$ \\
\hline TB- & $\left\{\left[\mathrm{Mg}_{0.68} \mathrm{Al}_{0.32}(\mathrm{OH})_{2}\right]\left[\mathrm{B}_{4} \mathrm{O}_{5}(\mathrm{OH})_{4}\right]_{0.160} \cdot 0.7 \mathrm{H}_{2} \mathrm{O}\right\}$ & 14.9 & 7.87 & 6.16 & 3.10 & 14.8 \\
$\mathrm{LDH} / \mathrm{MF}$ & $-0.03 \mathrm{MgFe}_{2} \mathrm{O}_{4}$ & $(15.1)$ & $(7.98)$ & $(6.50)$ & $(3.42)$ & $(12.88)$ \\
\hline
\end{tabular}

\subsection{Molecular simulations of TB-LDH structure and its hydration}

Based on the experimentally determined sample composition (TB-LDH: $\left.\left[\mathrm{Mg}_{0.67} \mathrm{Al}_{0.33}(\mathrm{OH})_{2}\right]\left[\mathrm{B}_{4} \mathrm{O}_{5}(\mathrm{OH})_{4}\right]_{0.165} \cdot 0.7 \mathrm{H}_{2} \mathrm{O}\right)$, the computational models were constructed assuming the presence of only tetraborate anions $\left[\mathrm{B}_{4} \mathrm{O}_{5}(\mathrm{OH})_{4}\right]^{2-}$ and $\mathrm{H}_{2} \mathrm{O}$ molecules in the 
interlayers of $\mathrm{Mg}_{2} \mathrm{Al}-\mathrm{LDH}$. Thus, the computational models corresponded to the structural

262 formula $\mathrm{Mg}_{4} \mathrm{Al}_{2}(\mathrm{OH})_{12}\left[\mathrm{~B}_{4} \mathrm{O}_{5}(\mathrm{OH})_{4}\right] \cdot n \mathrm{H}_{2} \mathrm{O}$, and each simulation supercell contained three

263 metal-hydroxide layers, $18\left[\mathrm{~B}_{4} \mathrm{O}_{5}(\mathrm{OH})_{4}\right]^{2-}$ anions (Fig. 2a), and a variable number of water 264 molecules, $n=0,2,4,6,8,10$ (Fig. 3).

265 Quantitative analysis of the LDH structural swelling upon hydration and determination 266 of the equilibrium water content in the interlayers represents a sensitive test of the quality of 267 the developed atomistic models [32,33]. The structure and energetics of LDH layer expansion 268 upon hydration was analyzed here by computing hydration energy defined as:

$$
\Delta U_{\text {hydr }}\left(N_{\mathrm{w}}\right)=\frac{\left\langle U\left(N_{\mathrm{w}}\right)\right\rangle-\langle U(0)\rangle}{N_{\mathrm{w}}}
$$

where $N_{\mathrm{w}}$ is the total number of water molecules in the simulated system, $U\left(N_{\mathrm{w}}\right)$ is the total potential energy of the system, and $U(0)$ is the total potential energy of the same system with

272 no water molecules. The hydration energy $\Delta U\left(N_{\mathrm{w}}\right)$ offers a simple and effective way to 273 quantitatively assess the affinity of water for the interlayers of clays and other swelling 274 materials [32-33, 52-53]. Since $\Delta U\left(N_{\mathrm{w}}\right)$ is the difference of energies between two structures 275 that differ only by their water content, one can expect that most of the possible inaccuracies in 276 the description of the crystal energy would cancel out. This is particularly true for the TB277 LDH systems simulated here, because the dominant contributions to the hydration energy 278 arise from long range electrostatic interactions and formation of hydrogen bonds between the 279 O-H groups of the metal hydroxide layers, the interlayer anions, and the $\mathrm{H}_{2} \mathrm{O}$ molecules. 


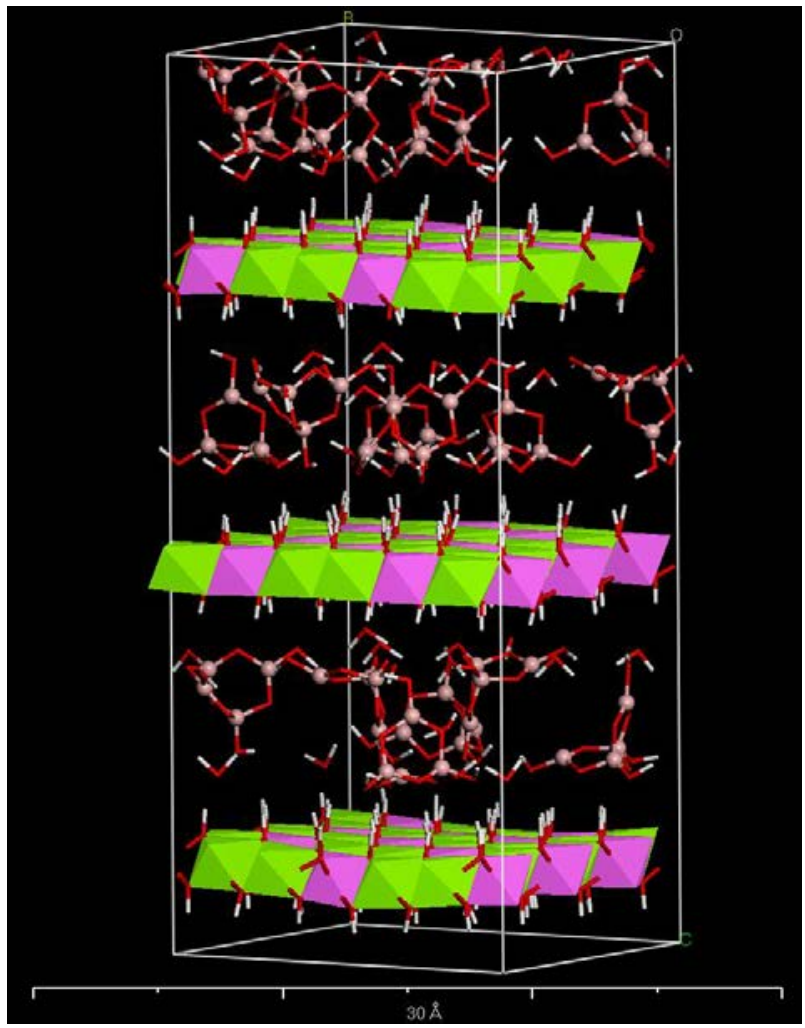

Fig. 3 A representative snapshot from MD simulations of $\mathrm{Mg}_{2} \mathrm{Al}-\mathrm{LDH}$ intercalated with $\mathrm{TB}$ at a normal hydration state of $n=2$. (Light green and pink octahedra: $\mathrm{Mg}^{2+}$ and $\mathrm{Al}^{3+}$ structural cations, respectively; TB anions are shown as in Fig.2, while $\mathrm{H}$ (white) and $\mathrm{O}$ (red) atoms of $\mathrm{H}_{2} \mathrm{O}$ molecules and surface $\mathrm{OH}$ groups are shown in stick representation.

The equilibrium $d$-spacing (Fig. 4a) of the completely dehydrated TB-LDH in our simulations is $11.36 \AA$, and it increases only slightly to $11.57 \AA$ at the hydration state characterized by $\mathrm{H}_{2} \mathrm{O} / \mathrm{TB}=2$ before growing further upon higher hydration. Both of these values are somewhat higher than the $d$-spacing of $10.89 \AA$ determined by XRD, but still within the accuracy of the current calculations. However, the resulting curves of the system hydration energy as a function of water content indicate that under ambient conditions the stable equilibrium hydration state should be expected at $n \sim 2$ (Fig. 4b), while the experimental data seem to imply that $n$ should be closer to 4. More accurate simulations should clarify this 
contradiction by developing a more consistent force field parameterization for boron within ClayFF [37]. However, it is important to note that the simulated swelling behavior of TBLDH in Fig. 4 is qualitatively and even quantitatively very similar to the swelling behavior of Mg-Al-LDH intercalated by glutamate - an anion of the same charge and approximately the same size [33].

$$
\left[\mathrm{Mg}_{4} \mathrm{Al}_{2}(\mathrm{OH})_{12}\right]\left[\mathrm{B}_{4} \mathrm{O}_{5}(\mathrm{OH})_{4}\right] \cdot n \mathrm{H}_{2} \mathrm{O}
$$
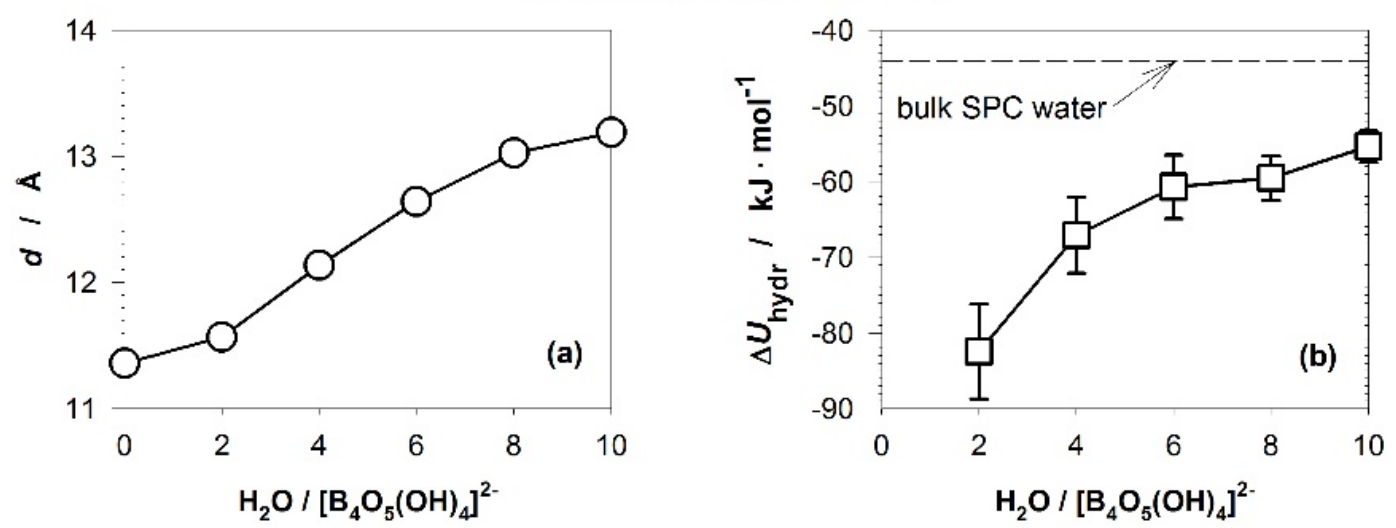

Fig. 4 The equilibrium layer spacing (a) and the hydration energy of the TB-LDH structure (b) as functions of the water content in the interlayers (number of $\mathrm{H}_{2} \mathrm{O}$ molecules per tetraborate anion).

\subsection{Particle characteristics}

Fig. 5 shows the nitrogen adsorption/desorption isotherms of TB-LDH and TBLDH/MF samples. The measured specific surface areas were 101 and $83 \mathrm{~m}^{2} / \mathrm{g}$, respectively. These values are large compared to typical values for hydrotalcite (HT)-like systems for which such values can be attained after thermal treatment [54]. The minimal hystereses in the curves (Type H1) indicated a narrow range of uniform mesopores and the absence of micropores [55]. 

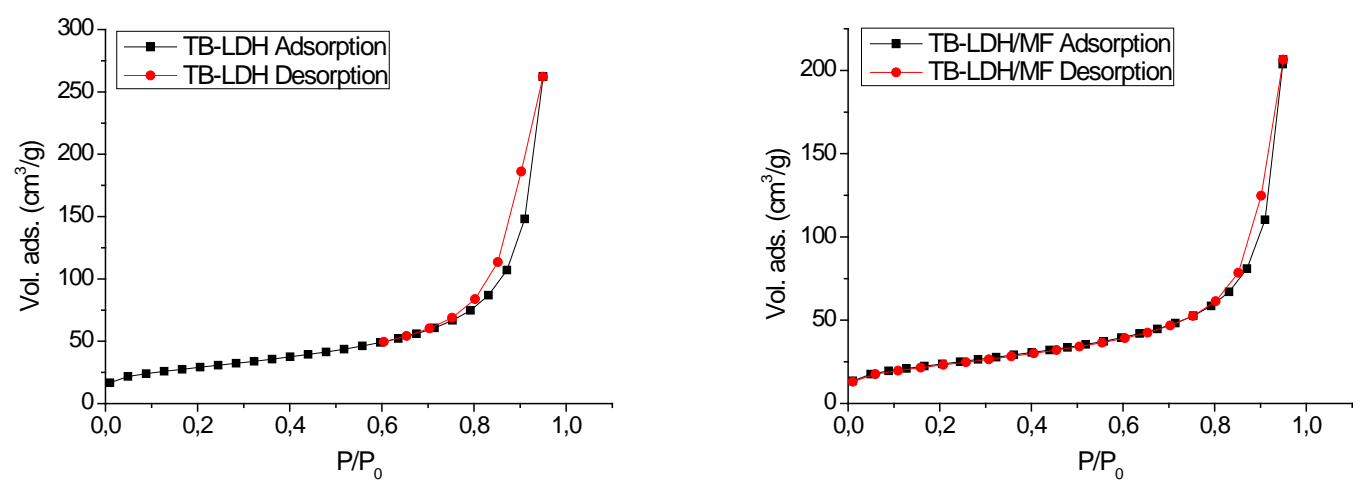

Fig. 5 Nitrogen adsorption isotherms of TB-LDH and TB-LDH/MF samples

TB-LDH and TB-LDH/MF suspensions were held in an ultrasonic bath for deaggregation before particle size distribution analysis. Usually, the maximum size values for large particles are expected to be shifted to lower values as the processing time in the ultrasonic chamber increases. However, different behaviors were observed for these samples, especially for the TB-LDH/MF. A monomodal distribution with a maximum of about 100 microns was observed for TB-LDH, while a complex particle size distribution was observed for sample TB-LDH/MF (Fig. S4). It is difficult to quantitatively determine the particle-size distribution for magnetic particles because the presence of aggregates of small crystallites is known to cause problems in the analysis of particle size [56]. The advantage of using SEM and TEM is that one physically observes the particles and obtains information not only about particle size but also their morphology. Fig. 6 shows the SEM images of the samples. The image of the original nitrate clay (LDH) clearly exhibited a layered structure. Stacking of hexagonal platelets with large surface areas in rose morphology is typical for such materials. The layer stacking in TB-LDH was not very clear since the interlayer space was enlarged by the incorporation of TB ions into the structure. The increase in the interlayer space induced by swelling due to intercalation of TB (and probably the different ionic strength of the solution where such a $\mathrm{NO}_{3} / \mathrm{TB}$ exchange has taken place) lead to a rearrangement of the primary LDH 
particles' morphology. For the magnetic core-shell TB-LDH/MF sample, a different image was noticed, showing clusters with sizes in the range of 50-150 nm. By electrostatic interaction, LDH layers were coated around magnetic cores in parallel to the surface of the nucleus and TB-LDH/MF nanocomposites having larger diameter were obtained without changing the core morphology.

A high resolution TEM image showed the polyhedral morphology of particles containing a TB-LDH shell of ca. 5-10 nm thickness around the polyhedral ca. 50-100 nm MF particles (Fig. 7). Arrangement of LDH plates in a thin shell around the polyhedral core particles resulted in a decrease in the specific surface area.

The room temperature magnetization curves for TB-LDH/MF and the core material itself, for comparison, are given in Fig. 8. The saturation magnetization value observed for the magnetic core $\left(\sigma_{\mathrm{s}}=29.6 \mathrm{emu} / \mathrm{g}\right)$ is characteristic for ferromagnetic spinel ferrites prepared by calcination of LDHs $[57,58]$. Saturation magnetization decreased to $\sigma_{\mathrm{s}}=2.19 \mathrm{emu} / \mathrm{g}$ when the MF core was coated with the non-magnetic TB-LDH shell which reduced the mole fraction of the magnetic core in the composite material. The enlarged inset of the magnetization curve showed no hysteresis indicating that TB-LDH/MF particles can behave as SPIONs (Superparamagnetic Iron Oxide Nanoparticles).
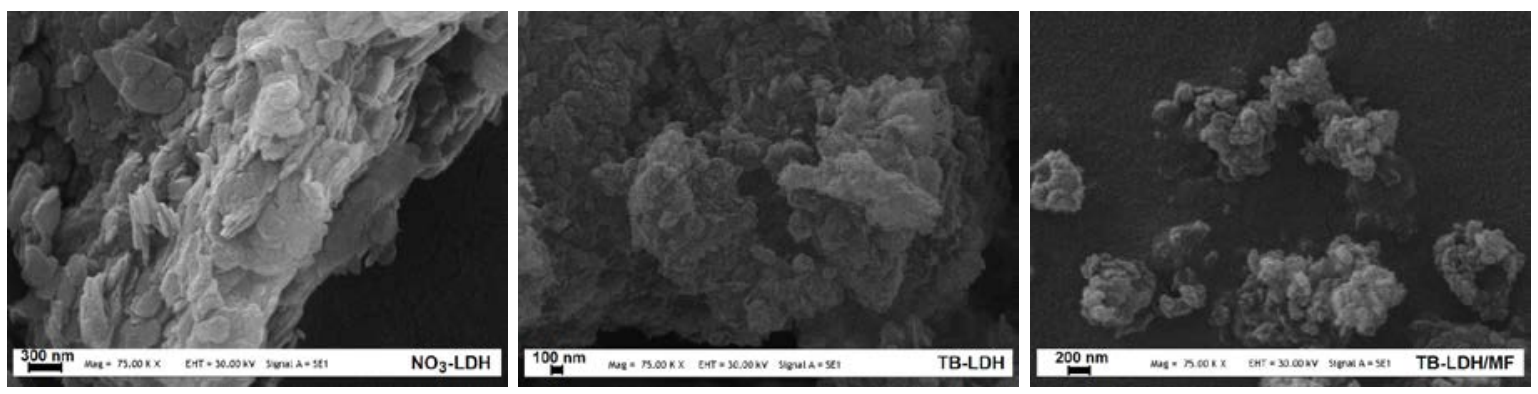

Fig. 6 SEM images of $\mathrm{NO}_{3}-\mathrm{LDH}$, TB-LDH and TB-LDH/MF 
352

353

354

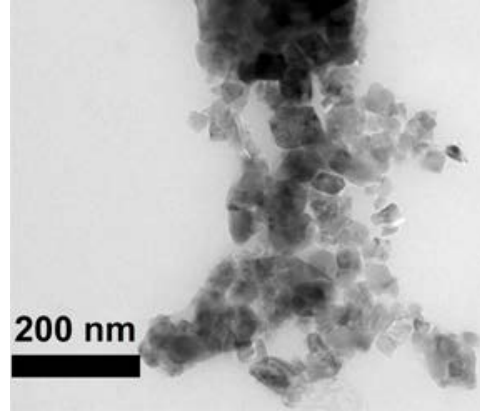

Fig. 7 TEM images of MF (left and middle), and TB-LDH/MF (right)

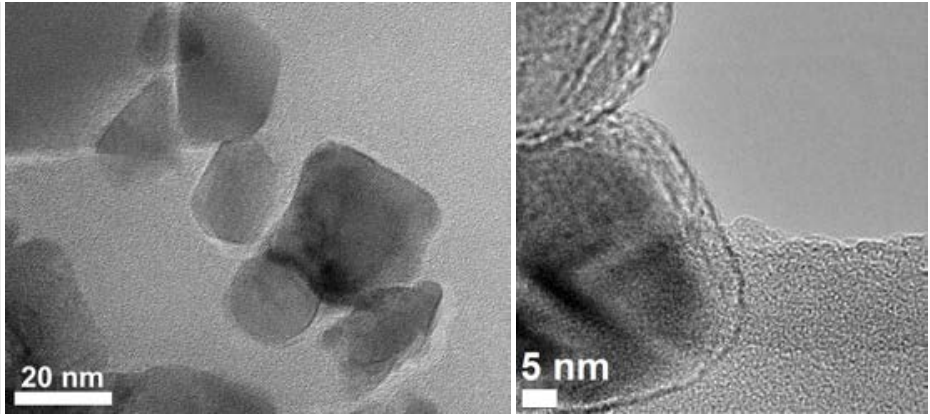

$20 \mathrm{~nm}$

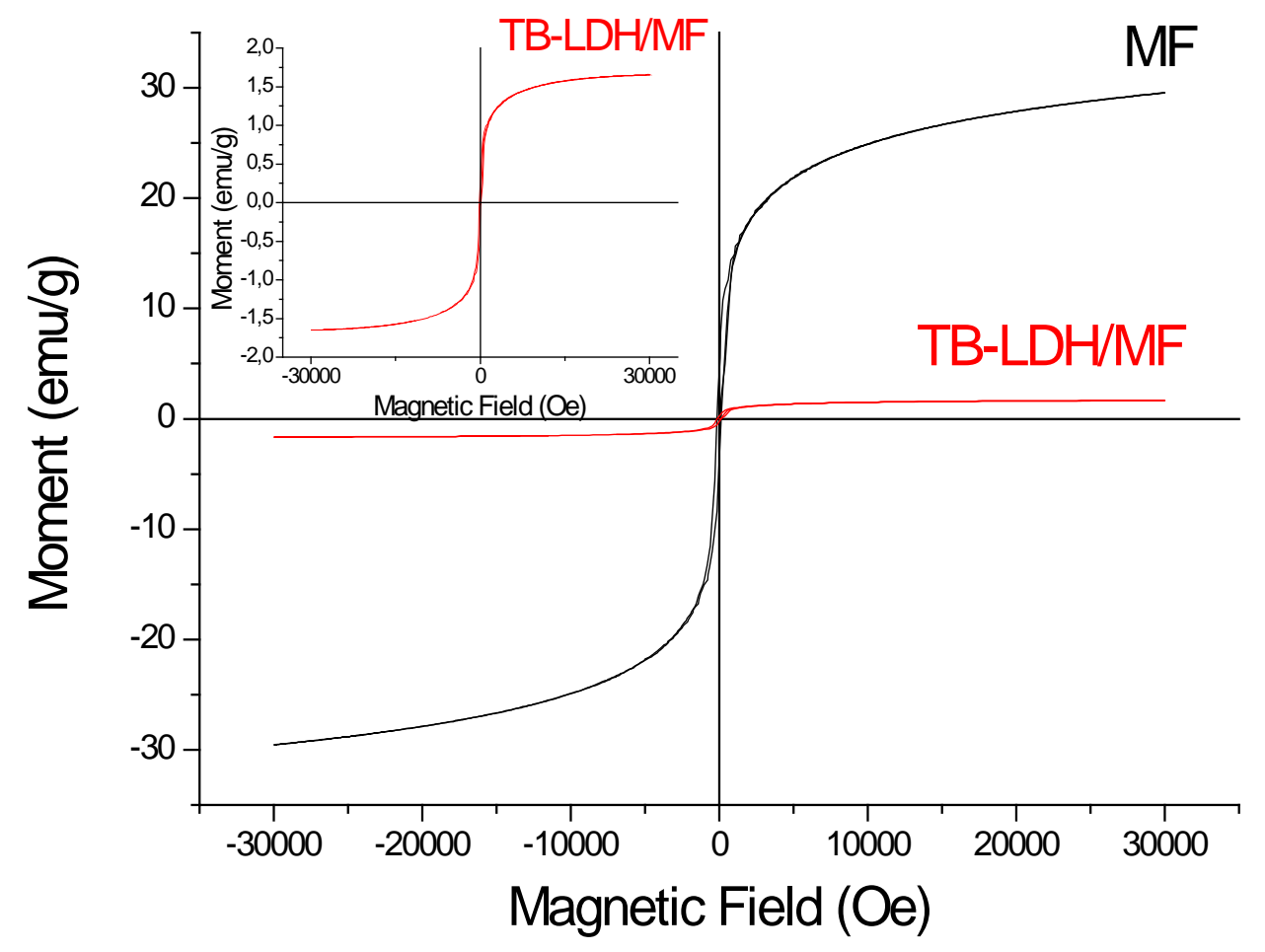

Fig. 8. Room temperature magnetization curves for MF and TB-LDH/MF

The properties summarized in Table 2 are promising for the use of TB-LDH and TB-

LDH/MF composite nanoparticles in potential biomedical applications [59]. Immobilization of the shell around the magnetic core did not cause any significant distortion in the LDH structure. XRD data revealed that the shell retains its layered structure after coating on the MF 
Table 2 Some characteristic properties of TB-LDH and TB-LDH/MF samples

\begin{tabular}{|c|c|c|c|c|c|c|}
\hline Sample & $\begin{array}{l}d_{003} \\
(\AA)\end{array}$ & $\begin{array}{c}\mathrm{B} \\
(\% \mathrm{w} / \mathrm{w})\end{array}$ & $\begin{array}{c}\text { Core } \\
\text { (\% w/w) }\end{array}$ & $\begin{array}{c}\sigma_{\mathrm{s}} \\
(\mathrm{emu} / \mathrm{g})\end{array}$ & $\begin{array}{l}\text { BET } \\
\text { specific } \\
\text { surface } \\
\text { area }\left(\mathrm{m}^{2} / \mathrm{g}\right)\end{array}$ & $\begin{array}{c}\text { Particle size } \\
\text { distribution }(\mu \mathrm{m})\end{array}$ \\
\hline TB-LDH & 10.89 & 7 & - & - & 101 & 100 (monomodal) \\
\hline $\begin{array}{l}\text { TB- } \\
\text { LDH/MF }\end{array}$ & 10.89 & 6.5 & 6 & 2.19 & 83 & complex distribution \\
\hline
\end{tabular}

The surface areas were comparable but larger for the nonmagnetic composite due to the stacking of the LDH platelets in rose morphology, which also offers the contribution of the inner surfaces. Nitrogen adsorption-desorption experiments showed that both materials have mesopores and can provide facile channels for electrolyte diffusion in drug delivery applications like mesoporous silica [60]. The sizes of the particles range in 50-150 nm approaching the range of biological compatibility and meeting the requirement for administration by injection [61]. 
amount recommended for the daily intake of people who are at risk of osteoporosis, osteoartrhritis, or cancer [17]. The nanocomposites contain ca. $10^{17}$ of B atoms (ca. $10^{16}$ of ${ }^{10} \mathrm{~B}$ isotope) per microgram, displaying the potential to be used in targeted BNCT applications as well [20].

\section{Conclusions}

This work covers the preparation and characterization of Mg-Al-LDH and also magnesium ferrite core-Mg-Al-LDH shell nanocomposites as boron carriers and magnetic targeting agents for potential biomedical applications.

Powder-XRD and computational modeling results confirmed the intercalation of TB ions in the LDH galleries in nearly vertical (oblique) orientation which stabilizes the LDH structure through hydrogen bonding and electrostatic interactions. The structural behavior of the interlayer TB ions was modelled to assess the H-bonding interactions and energetics of hydration. However, further improvement of the parametrization of interatomic interactions involving TB ions seems to be necessary in order to achieve better agreement with XRD data. Chemical analysis results indicated high entrapment efficiency of the LDH matrix for TB ions. Both the magnetic and nonmagnetic nanocomposites were found to contain $6-7 \%$ boron, meeting the dosage requirements for boron medication including BNCT. The nanocomposites were found to have suitable particle characteristics for the emerging medical applications of boron containing compounds.

Loading of polyborate ions within the LDH material along with superparamagnetic iron oxide nanoparticles represents another advantage for delivery. TB-LDH/MF nanoparticles can literally drag TB ions to their target site in the body under the influence of an applied magnet field. 
Powder XRD patterns, FT-IR spectra and TGA/D-TGA curves of $\mathrm{NO}_{3}-\mathrm{LDH}$, TB$404 \mathrm{LDH}, \mathrm{NO}_{3}-\mathrm{LDH} / \mathrm{MF}$ and TB-LDH /MF, Particle size distribution curves of TB-LDH and 405 TB-LDH/MF. A complete list of the force field parameters describing the energy of 406 interatomic interactions in the simulated systems is also provided in Supplementary 407 Information together with the description of how these parameters were used in the present 408 calculations.

409

\section{Acknowledgements}

This work has been supported by Hacettepe University through project: 01201601 412 002. A.G.K. also acknowledges support of the Basic Research Program at the National 413 Research University Higher School of Economics within the framework of a subsidy by the 414 Russian Academic Excellence Project “5-100”. 


\section{References}

417 [1] V. Rives (ed) Layered Double Hydroxides: Present and Future (Nova Science $418 \quad$ Publishers, New York, 2001)

419 [2] B. Zumreoglu-Karan, A. N. Ay, Chem. Papers 66, 1-10 (2012)

420 [3] W. Jiang, J. Wu, R. Tian, J. Porous Mater. 24, 257-265 (2017)

421

[4] K. H. Goh, T.T. Lim, Z. Dong, Water Research 42 1343-1368 (2008)

422 [5] T. Li, H. N. Miras, Y. F. Song, Catalysts 7, 260-277 (2017)

423 [6] F. L. Theiss, G. A. Ayoko, R.L. Frost, J. Coll. Interface Sci. 402, 114-121 (2013)

424 [7] L. Shi, D. Li, J. Wang, S. Li, Sufeng, D. G. Evans, X. Duan, Clays Clay Miner. 53, 425 294-300 (2005)

426

[8] G. Elmaci, O. Icten, A. N. Ay, B. Zümreoglu-Karan, Appl. Clay. Sci. 107, 117-121

427 (2015)

428

429

[9] G. Varga, S. Muráth, Á. Bajcsi, Á. Kukove, Z. Kónya, P. Sipos, I. Pálinkó, Reac. Kinet. Mech. Cat. 121, 241-254(2017)

430

[10] L. Li, S. Ma, X. Liu, Y. Yue, J. Hui, R. Xu, Y. Bao, J. Rocha, Chem. Mater. 8, 204-208

431 (1996)

432

[11] M. Del Arco, S. Gutierrez, C. Martin, V. Rives, J. Rocha, J. Solid State Chem. 151, $272-280(2000)$

[12] A. N. Ay, B. Zümreoglu-Karan, A. Temel, L. Mafra, Appl. Clay Sci. 51, 308-316 (2011)

436

437

[13] V. Rives, M. del Arco, C. Martín, Appl. Clay. Sci. 88-89, 239-269 (2014)

[14] C.D. Hunt, J. Trace Elem. Med. Biol. 26, 157-160 (2012)

[15] B. C. Das, P. Thapa, R. Karki, C. Schinke, S. Das, S. Kambhampati, S. K Banerjee, P. V. Veldhuizen, A. Verma, L. M. Weiss, T. Evans, Future Med. Chem. 5, 653-676 (2013) 
[16] B. Zumreoglu-Karan, D.A. Kose, Pure Appl. Chem. 87, 155-162 (2015)

[17] L. Pizzorno, Integr. Med. 14, 35-48 (2015)

[18] A.K. García-Ávila, E. D. Farfán-García, J. A. Guevara-Salazar, J. G. TrujilloFerrara, M. A. Soriano-Ursúa, World J. Transl. Med. 12, 1-9 (2017)

[19] E. Hey-Hawkins, C. Vinas Teixidor (eds) Boron Based Compounds: Potential and Emerging Applications in Medicine (Wiley, 2018)

[20] N.S. Hosmane, Boron Science: New Technologies and Applications (CRC Press, Boca Raton, FL, 2011) p. 147

[21] A. N. Ay, H. Akar, A. Zaulet, C. Viňas, F. Teixidor, B. Zumreoglu-Karan, Dalton Trans. 46, 3303-3310 (2017)

[22] G. Choi, I.-R. Jeon, H. Piao, J.-H. Choy, Adv. Funct. Mater. 28, 1704470 (2017)

[23] W. W. Ku, R. E. Chapin, R. F. Moseman, R. E. Brink, K. D. Pierce, K. Y. Adams, Toxicol. Appl. Pharmacol. 111, 145-151 (1991)

[24] C. D. Hunt, in Encyclopedia of Dietary Supplements, ed. by P. M. Coates, M. R. Blackman, G. M. Cragg, M. Levine, J. Moss, J. D.White, 2nd ed. (CRC Press, New York, 2004) p. 55

[25] H. Kempe, S. A. Kates, M. Kempe, Expert Rev. Med. Devices 8, 291-294 (2011)

[26] J. Cabrera-González, L. Cabana, B. Ballesteros, G. Tobias, R. Núñez, Chem. Eur. Journal 22, 5096-5101 (2016)

[27] O. Icten, N. Hosmane, D. A. Kose, B. Zumreoglu-Karan, New J. Chem. 41, 3646-3652 (2017)

[28] E. Oleshkevich, F. Teixidor, A. Rosell, C. Vinas, Inorg. Chem. 57, 462-470 (2018)

[29] O. Icten, D. A. Kose, S. J. Matissek, J. A. Misurelli, S. F. Elsawa, N. S. Hosmane, B. Zumreoglu-Karan, Mat. Sci. Eng. C 92, 317-328 (2018)

[30] A. N. Ay, D. Konuk, B. Zumreoglu-Karan, Mat. Sci. Eng. C 31, 851-857 (2011) 
[31] M.P. Allen, D.J. Tildesley, D. J. Computer Simulation of Liquids, 2nd Edition (Oxford University Press, New York, 2017)

[32] P. P. Kumar, A. G. Kalinichev, R. J. Kirkpatrick, J. Phys. Chem. C. 111, 13517-13523 (2007)

[33] A. G. Kalinichev, P.P. Kumar, R. J. Kirkpatrick, Philos. Mag. 90 2475-2488 (2010)

[34] M. Bellotto, B. Rebours, O. Clause, J. Lynch, D. Bazin, E. Elkaim. J. Phys. Chem. 100, 8527-8534 (1996)

[35] M.Vucelic, W.Jones, G.D.Moggridge, Clays and Clay Minerals 45, 803-813 (1997)

[36] K.Yao, M.Taniguchi, M.Nakata, M.Takahashi, A.Yamagishi, Langmuir 14, 2410-2414 (1998)

[37] R.T.Cygan, J.J.Liang, A.G.Kalinichev, J.Phys.Chem. B 108, 1255-1266 (2004)

[38] S. L. Mayo, B. D. Olafson, W. A. Goddard, J. Phys. Chem. 94, 8897-8909 (1990)

[39] A. K. Rappe, W. A. Goddard, J. Phys. Chem. 95, 3358-3363 (1991)

[40] S.P. Newman, T. Di Cristina, P.V. Coveney. W. Jones, Langmuir 18, 2933-2939 (2002)

[41] R.J. Kirkpatrick, A.G. Kalinichev, J. Wang, X. Hou, J.E. Amonette. Molecular modeling of the vibrational spectra of interlayer and surface species of layered double hydroxides. In: The Application of Vibrational Spectroscopy to Clay Minerals and Layered Double Hydroxides, ed. by J.T.Kloprogge, (The Clay Mineral Society, Aurora, CO, 2005), pp. 239-285

[42] BIOVIA, Inc. http://accelrys.com/products/datasheets/materials-studiooverview.pdf, 2017.

[43] F. Cavani, F. Trifiro, A. Vaccari, Catal. Today 11, 173-301 (1991)

[44] A. N. Ay, B. Zumreoglu-Karan, A. Temel, Micropor. Mesopor. Mater. 98, 1-5 (2007) 
[45] N. T. Whilton, P.J. Vickers, S. Mann, J. Mater. Chem. 7, 1623-1629 (1997)

[46] N. Morimoto, Mineral. Journal 2, 1-18 (1956)

[47] C. Weir, Journal of Research NBS-A 70, 153-164 (1966)

[48] C. G. Salentine, Inorg. Chem. 22, 3920-3924 (1983)

[49] J. M. Simon, R. A. Smith, Glass Technology 41, 169-173 (2000)

[50] M. A. Beckett, A. Davies, C.D. Thomas, Comput. Theoret. Chem. 1044, 74-79 (2014)

[51] F. M. Labajos, V. Rives, M. A. Ulibarri, J. Mater. Sci. 27, 1546-1552 (1992)

[52] R. J. Kirkpatrick, A. G. Kalinichev, X. Hou, L. Struble, Mater. Struct. 38, 449-458 (2005)

[53] B. F. Ngouana-Wakou, A. G. Kalinichev, J. Phys. Chem. C 118, 12758-12773 (2014)

[54] M. del Arco, V. Rives, R. Trujillano, Stud. Surf. Sci. Catal. 87, 507-515 (1994)

[55] M. Thommes, K. Kaneko, A. V. Neimark, J. P. Olivier, F. Rodriguez-Reinoso, J. Rouquerol, K. S. W. Sing, Pure Appl. Chem. 87, 1051-1069 (2015)

[56] A. Weibel, R. Bouchet, F. Boulch, P. Knauth, Chem. Mater. 17, 2378-2385 (2005)

[57] H. Zhang, K. Zou, H. Sun, X. Duan, J. Solid. State. Chem. 178, 3485-3493 (2005)

[58] J. Liu, F. Li, D. G. Evans, X. Duan, Chem. Commun. 542-543 (2003)

[59] S. Zanganeh, J. Q. Ho, M. Aieneravaie, M. Erfanzadeh, M. Pauliah, R. Spitler, in Iron Oxide Nanoparticles for Biomedical Applications, ed. by M. Mahmoudi, S. Laurent (Elsevier, 2018) pp 247-271

[60] A. Datt, N. Ndiege, S.C. Larsen, in Nanomaterials for Biomedicine, ed. by R. Nagarajan, ACS Symp. Series 1119, 239-258 (2012)

[61] A. H. Faraji, P. Wipf, Bioorg. Med. Chem. 17, 2950-2962 (2009) 